\title{
The influence of climate change and human activities on runoff in the middle reaches of the Huaihe River Basin, China
}

\author{
GAO Chao ${ }^{1}$, RUAN Tian ${ }^{2,3}$
}

1. Department of Geography and Spatial Information Techniques, Ningbo University, Ningbo 315211, Zhejiang, China;

2. College of Territorial Resources and Tourism, Anhui Normal University, Wuhu 241000, Anhui, China;

3. Climate Change and Water Resource Center of Jiang-Huai Basin, Anhui Normal University, Wuhu 241000, Anhui, China

\begin{abstract}
This study presents a soil and water integrated model (SWIM) and associated statistical analyses for the Huaihe River Basin (HRB) based on daily meteorological, river runoff, and water resource data encompassing the period between 1959 and 2015 . The aim of this research is to quantitatively analyze the rate of contribution of upstream runoff to that of the midstream as well as the influence of climate change and human activities in this section of the river. Our goal is to explain why extreme precipitation is concentrated in the upper reaches of the HRB while floods tend to occur frequently in the middle reaches of this river basin. Results show that the rate of contribution of precipitation to runoff in the upper reaches of the HRB is significantly higher than temperature. Data show that the maximum contribution rate of upstream runoff to that of the midstream can be as high as $2.23 \%$, while the contribution of temperature is just $0.38 \%$. In contrast, the rate of contribution of human activities to runoff is $87.20 \%$ in the middle reaches of the HRB, while that due to climate change is $12.80 \%$. Frequent flood disasters therefore occur in the middle reaches of the HRB because of the combined effects of extreme precipitation in the upper reaches and human activities in the middle sections.
\end{abstract}

Keywords: runoff; climate change; human activity; contribution rate; Huaihe River Basin

\section{Introduction}

The global climate system has changed significantly over the last century. Coupled with intense human activities, the spatiotemporal distribution of water resources has tended to become increasingly imbalanced, while extreme events (such as floods and droughts) have occurred with increasing frequency (Song et al., 2013; Gao and Zhang, 2016; Birkinshaw et al., 2017). Thus, the risks of natural disasters and other problems associated with environmental change

Received: 2017-06-08 Accepted: 2017-08-16

Foundation: National Natural Science Foundation of China, No.41571018

Author: Gao Chao (1978-), PhD and Professor, specialized in climate change and hydrology and water resources. E-mail: gaoqinchao1@163.com 
have aroused a great concern to researchers (Pierrehumbert, 2002; Wang et al., 2009; Chen et al., 2010; He et al., 2016). It is urgent to carry out flood risk assessments and associated research to improve the accuracy and suitability of disaster prediction (Piao et al., 2010).

Researchers from around the world have tended to concur that flood risk is the result of a combination of factors, including flood hazard as well as the exposure and vulnerability of hazard-bearing bodies. Thus, flood risk is closely related to the extreme precipitation that leads to runoff (Gao et al., 2015; Aamerya et al., 2016). The key consideration in past flood risk assessments has been the impact of precipitation on local runoff, including the impact of upstream precipitation on runoff in these river sections. However, due to its particular climatic conditions and geographical environment, extreme precipitation has tended to occur mainly in the upper reaches of the Huaihe River Basin (HRB) (Lu et al., 2015). At the same time, due to a large stream gradient and rapid flood discharge, the middle reaches of the HRB have frequently been flooded. The specific conditions influencing this basin mean attempt to separate the impact of climate change on runoff from that of human activities in the middle and upper reaches of the HRB will enable improvements to the accuracy of flood risk assessment. In this context, it is noteworthy that previous research on the combined effects of climate change and human activities on runoff have addressed two main themes. First, the contribution of climate change and human activities to variation in runoff has been studied via precipitation observations, runoff and calculated evaporation sequence changes (Lan et al., 2010; Bao et al., 2012; Deng et al., 2017), while secondly the evolution and role of natural and artificial water cycles within a basin (i.e., the social water cycle) have also been addressed (Zhang et al., 2000; Ahn et al., 2017). We utilize the first of these approaches in this study as it is relatively simple and easy to apply. Investigation of the social water cycle requires relatively more hydrometeorological and socioeconomic data and therefore necessitates more intensive research (Sun and Li, 2014).

In terms of specific methods, research on the impact of climate change on runoff include the watershed contrast method, an effective approach that can be applied to eliminate the influence of climate change in studies on small watersheds. This contrast method is, however, more problematic to apply to larger-scale watersheds (Mladjic et al., 2011). A second statistical approach (Piao et al., 2010; Gao et al., 2015; Lu et al., 2015) is also available, based on the analysis of hydrometeorological time series data. The modeling process that underlies this method is relatively simple but it does not take into account underlying surface factors. Thus, use of a third approach, the hydrological modeling method (Wang et al., 2002; He et al., 2015; Ma et al., 2015), is preferable as it takes into account the distribution of a given hydrological system as well as physical mechanisms in combination with past empirical modeling. This approach is also preferable because it also incorporates the underlying geographical environment, including human activities. The hydrological modeling approach is an effective research method because it can be used to simulate water resources affected by both climate change and human activities.

The results of previous research have demonstrated that human activities likely exert a greater impact on runoff than climate change (Wang et al., 2002; Mladjic et al., 2011; Sun and Li., 2014; Wu et al., 2016). Anthropogenic impacts on runoff are mainly due to land use changes, as well as artificial water use, non-point source pollution, the introduction of sediment into water courses, and eco-hydrological responses (Xia, 2009; Chen et al., 2010; 
Zhang et al., 2012; Bi et al., 2013). Research in this area has also passed through three evolutionary states, from the initial use of simple statistical reduction calculations to the application of rainfall-runoff relationship models, and, most recently, to the development of distributed hydrological modeling research methods (Liew and Garbrecht, 2003; Li et al., 2007; Juckem et al., 2008). A distributed hydrological model is therefore one of the most appropriate tools currently available for studying the impacts of climate change and human activities on runoff (Tong et al., 2012; López-Moreno et al., 2014).

This paper quantitatively evaluates the contribution rate of upstream runoff to that of the midstream river section as well as the influence of climate change and human activities. The results of this study provide an explanation for the concentration of extreme precipitation events in the upper reaches of the HRB while floods tend to occur frequently in the middle reaches of this basin. The results of this study are also of practical significance for HRB flood risk assessment.

\section{Study area}

The HRB $\left(30^{\circ} 55^{\prime}-36^{\circ} 36^{\prime} \mathrm{N}, 111^{\circ} 55^{\prime}-121^{\circ} 25^{\prime} \mathrm{E}\right)$ is located in eastern China in the transitional zone between the north and south of the country. As a result of its unique location as well as the fact that this region is affected by both climate change and human activities, flood-related disasters within the HRB have become increasingly frequent. A series of spatial distribution maps based on extreme precipitation data are presented here for the middle and upper reaches of the HRB; these maps illustrate county-level flood disaster loss data for the period between 1984 and 2008 (Figure 1). It is noteworthy that previous research has demonstrated that extreme HRB precipitation (Lu et al., 2015) is mainly concentrated in the southwestern upper reaches of this basin, while the more serious flood-related disasters tend to occur within central areas, specifically in the middle reaches of the basin. Because the entire HRB covers a very large area, we selected the middle sections of this basin prone to flood disasters as well as the upstream region characterized by a high frequency of extreme precipitation as the study area for this research. This approach reduces the error in our hydrological model simulation (Figure 1) and encompasses the middle and upper reaches of the HRB from Tongbai to the Wujiadu hydrological station. Wangjiaba and Wujiadu was designated as water outlets for the purposes of this research and the sub-watershed was divided into the middle and upper reaches of the study area, respectively (Figure 2).
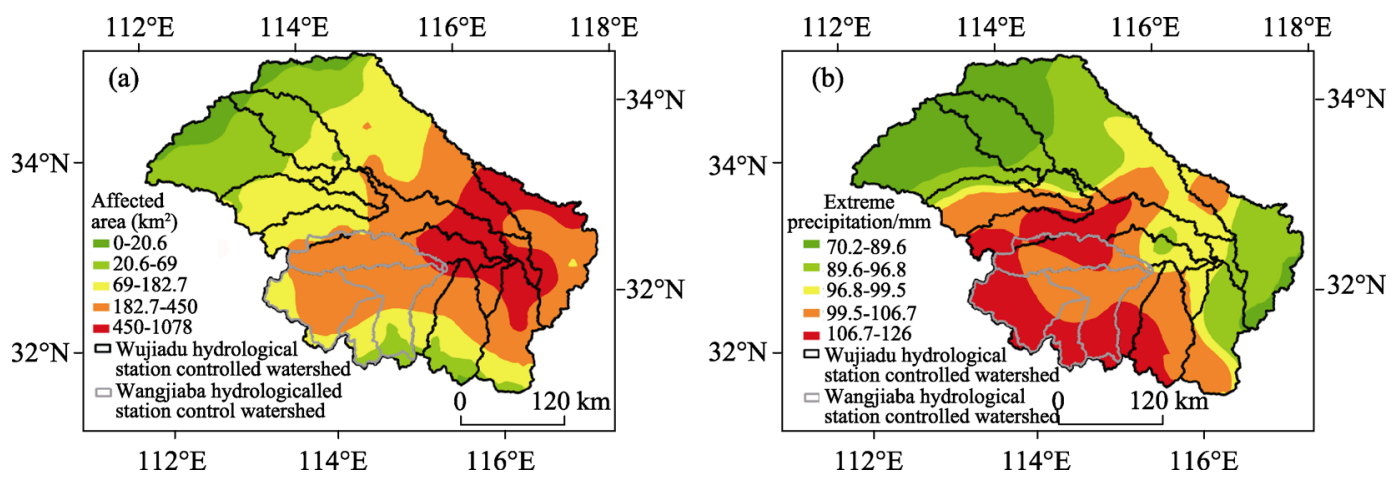

Figure 1 Maps illustrating the flood disaster affected areas (a) and spatial distribution of extreme precipitation (b) in the middle and upper reaches of the HRB 


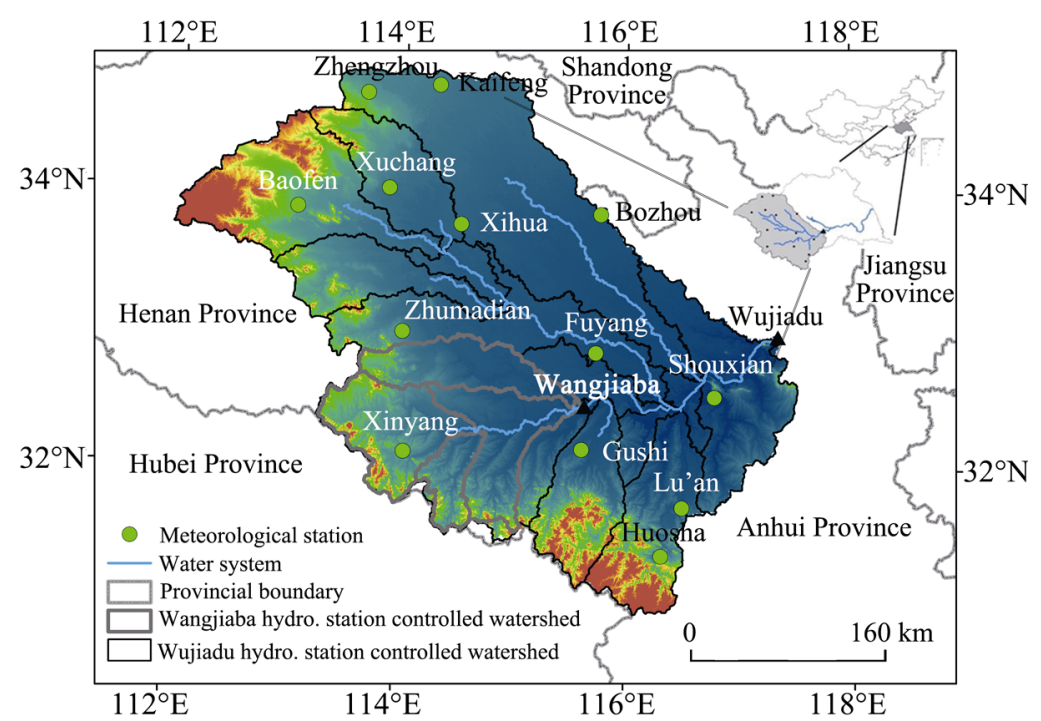

Figure 2 Map showing the study area as well as meteorological stations, the drainage system, and watershed

\section{Data and methods}

\subsection{Data}

The meteorological data used in this study was collected by the National Climate Center of China Meteorological Administration. Thus, daily observation data from 13 meteorological stations (Figure 2) throughout the middle and upper reaches of the HRB were collated for the period between 1959 and 2008. Data include maximum, minimum, and average temperature, as well as precipitation, sunshine hours, and daily radiation. Daily runoff data for the period between 1959 and 2008 were obtained from Wangjiaba and Wujiadu stations.

We utilized a digital elevation model (DEM) for the middle and upper reaches of the HRB that is based on Shuttle Radar Topography Mission data at a spatial resolution of $90 \mathrm{~m}$. This DEM was downloaded from the geospatial data cloud site of the Chinese Academy of Sciences (CAS) (http://www.gscloud.cn); soil data at a 1:4 million scale were used in this analysis, obtained from the United Nations Food and Agriculture Organization world soil database (http://www.fao.org), while land use data (also at a 1:4 million scale) was downloaded from the data Center for Resources and Environmental Sciences, CAS (http://www.resdc.cn). This analysis encompasses the time period between 1980 and 2000 and all data were re-sampled to a uniform spatial resolution of $400 \mathrm{~m}$. Reservoir quantity and water storage data between 1997 and 2015 were extracted from the HRB Water Resources Bulletin, while data on human activities between 1996 and 2015, including crop acreage, gross domestic product (GDP), and urbanization rate, were extracted from the regional statistical yearbook.

\subsection{Methods}

\subsubsection{Precipitation and temperature contribution rates}

We derived the relative runoff contribution rates of precipitation, temperature, and other meteorological factors by multiplying runoff sensitivity coefficients to meteorological fac- 
tors as well as the relative changes in these factors over multiple years using Equation 1 and Equation 2 (Dong et al., 2015), as follows:

$$
\begin{aligned}
\operatorname{Con}_{v i}=S_{v i} \times R C_{v i} \\
R C_{v i}=(n \times \text { Trend }) /|a v| \times 100 \%
\end{aligned}
$$

where $v i$ denotes the meteorological factor, while $\operatorname{Con}_{v i}$ signifies the contribution rate of $v i$ to runoff variation, $S_{v i}$ is the sensitivity coefficient of $v i$ to runoff, $R C_{v i}$ denotes the relative change of $v i$ over multiple years, $n$ is time, $a v$ is the average value of $v i$ between 1959 and 2008, and Trend stands for the annual rate of change. This latter component was calculated using trend analysis.

The sensitivity coefficient of runoff to precipitation and temperature was obtained using Equation (3) (Dong et al., 2015), as follows:

$$
C_{v x} \times \Delta t+C_{v y} \times \Delta p=\delta(\Delta p, \Delta t)
$$

where $C_{v x}$ is the sensitivity coefficient of runoff change to temperature change, $\Delta t$ is temperature change, $C_{v y}$ is the sensitivity coefficient of runoff change to precipitation change, $\Delta p$ is the precipitation change, and $\delta(\Delta p, \Delta t)$ is the rate of runoff change. As the units of $\Delta t$, $\Delta p$, and $\delta(\Delta p, \Delta t)$ are not uniform, z-scores from the software SPSS were used to standardize these data.

\subsubsection{Runoff contribution rate}

Midstream runoff in the HRB is mainly comprised of precipitation in the middle reaches as well as upstream runoff. Thus, we utilized the ratio of upstream to midstream runoff to calculate the relative contribution rates in each case using Equation (4), as follows:

$$
\eta=\frac{Q_{i}}{Q_{j}}
$$

where $\eta, Q_{i}$, and $Q_{j}$ refer to the contribution rates of upstream to midstream, upstream $\left(\mathrm{m}^{3} \cdot \mathrm{s}^{-1}\right)$, and midstream runoff $\left(\mathrm{m}^{3} \cdot \mathrm{s}^{-1}\right)$, respectively.

\subsubsection{Quantitative analysis of climate change and human activities}

In order to quantitatively analyze the effects of climate change and human activities on runoff in the middle reaches of the HRB, we used Mann-Kendall (MK) and sliding T-tests to determine runoff change points throughout the region. We then determined the base and evaluation periods for midstream runoff; of these, the first is a natural period where runoff is not affected by human activities, while human activities do play a role within the evaluation period. The main impact of human activities is revealed by land use types; thus, we initially applied a SWIM calibrated with the meteorological data input during the base period in order to simulate the runoff. Land use parameters were then held unchanged while meteorological data for the evaluation period were input into the model to simulate runoff given the impacts of climate change. Lastly, both meteorological and land use data were input into the model to simulate runoff due to the combined influence of both climate change and human activities throughout the evaluation period. A series of equations from Wang et al. (2006) were used for these calculations, as follows:

$$
\begin{gathered}
\Delta W_{\mathrm{T}}=W_{\mathrm{HR}}-W_{\mathrm{B}} \\
\Delta W_{\mathrm{H}}=W_{\mathrm{HR}}-W_{\mathrm{HN}}
\end{gathered}
$$




$$
\begin{array}{r}
\Delta W_{\mathrm{C}}=W_{\mathrm{HN}}-W_{\mathrm{B}} \\
\eta_{\mathrm{H}}=\Delta W_{\mathrm{H}} / \Delta W_{\mathrm{T}} \times 100 \% \\
\eta_{\mathrm{C}}=\Delta W_{\mathrm{C}} / \Delta W_{\mathrm{T}} \times 100 \%
\end{array}
$$

where $W_{\mathrm{B}}$ denotes simulated runoff during the base period, while $W_{\mathrm{HN}}$ refers to simulated runoff that only takes into account climate change impacts during the evaluation period. Similarly, $\Delta W_{\mathrm{T}}$ refers to the impact of human activities and climate change on runoff volume during the evaluation period, while $\Delta W_{\mathrm{H}}$ and $\Delta W_{\mathrm{C}}$ refer to the impact of human activities and climate change on runoff volumes, respectively, during the evaluation period. Finally, $\eta_{\mathrm{C}}$ and $\eta_{\mathrm{H}}$ refer to the contribution rates of climate change and human activities on runoff during the evaluation period, respectively.

\section{Analytical results}

\subsection{SWIM suitability analysis}

The use of a SWIM in the context of an analysis of this type was first proposed by the Potsdam Climate Impact Research Institute, Germany. Subsequent use of this approach has been enhanced by development of the soil and water assessment tool and MATSALU models that enable improved runoff simulations in small scale watersheds (Krysanova et al., 1989). The latter of these two models was developed in Estonia for application to the Matsalu Bay agricultural watershed in the Baltic Sea. Thus, building on these previous approaches, we assessed the applicability of our model by using the Nash efficiency (NSE) coefficient; the closer a NSE efficiency coefficient value is to one, the more accurate the simulation results (Gao and Jin, 2012). We selected the period between 1959 and 1988 as the calibration period for this analysis and the period between 1989 and 2008 as the validation period. Data show (Figure 3) that SWIM application accurately simulated daily runoff in the upstream area of the HRB, as resultant NSE values are 0.70 and 0.81 during the calibration and validation periods, respectively. Additional simulation results (Figure 4) also show that the SWIM also accurately simulates daily runoff within the central part of the HRB; resultant NSE values in this case are 0.72 and 0.78 for the calibration and validation periods, respectively. A SWIM can therefore be used to assess the impacts of climate change on river runoff in both the middle and upper reaches of the HRB.
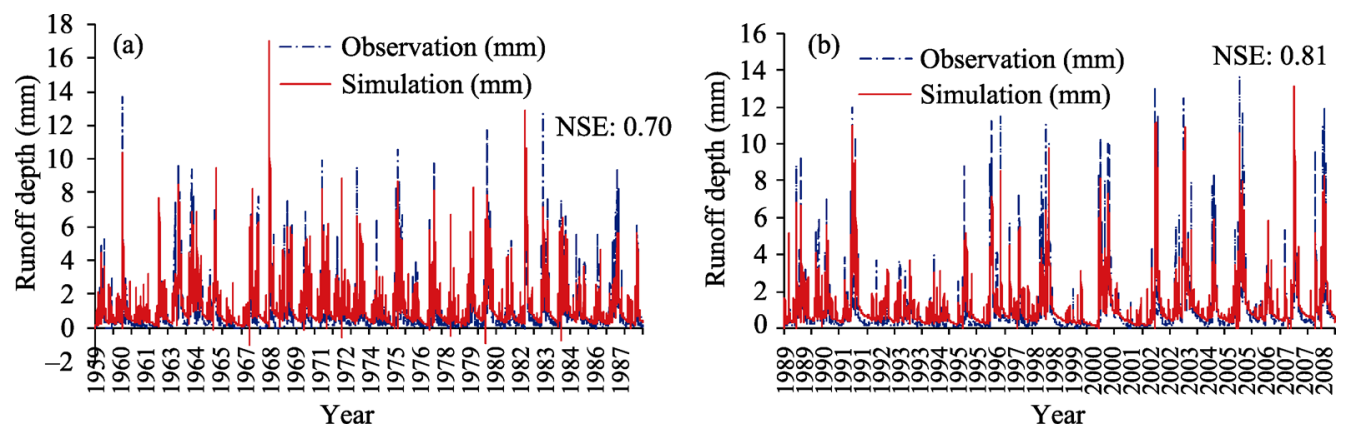

Figure 3 Graphs showing SWIM-simulated daily runoff depths for the upper reaches of the HRB during the calibration between 1959 and 1988 (a) and validation between 1989 and 2008 (b) periods of this study 

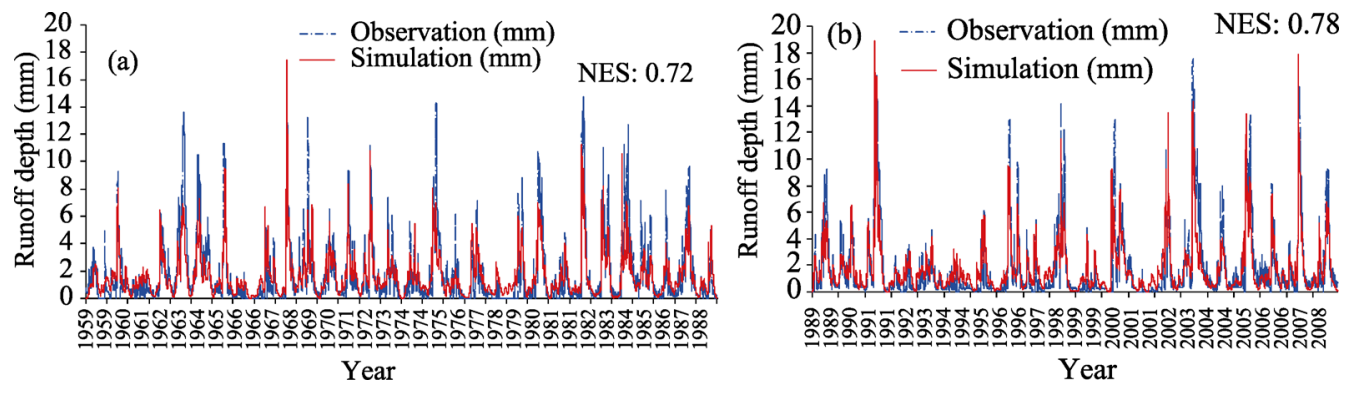

Figure 4 Graphs showing SWIM-simulated daily runoff depths for the middle reaches of the HRB during the calibration between 1959 and 1988 (a) and validation between 1989 and 2008 (b) periods of this study

\subsection{Contribution rate of climate factors}

4.2.1 Runoff versus temperature and precipitation sensitivity coefficients

The sensitivity of regional hydrological changes due to climate is usually based on the assumption that scenarios for the latter drive models for the former. Thus, a combination of precipitation and temperature change are usually input into climate change modeling scenarios; on the basis of observed trends within the HRB, we assume that plots for the upstream region of this river basin change along a scale of $-20 \%,-10 \%, 0 \%,+10 \%$, and $+20 \%$ for precipitation alongside temperature changes of $-1{ }^{\circ} \mathrm{C}, 0^{\circ} \mathrm{C},+1^{\circ} \mathrm{C},+2^{\circ} \mathrm{C}$, and $+3{ }^{\circ} \mathrm{C}$. Our model allows for the construction of 25 different climate scenarios within which runoff is simulated; thus, on the basis of these runoff changes, sensitivity to climate change can be assessed.

The SWIM results presented in Table 1 show that when precipitation is constant, a smaller change in runoff with temperature will be seen. In contrast, when temperature is constant, the precipitation change rate increases from an initial constant to a linear rate of increase while the runoff change rate also increases up to a level as high as $20 \%$. The precipitation change rate decreases from an initial constant to a linear rate of decrease while the runoff rate of change has a tendency to decrease, but the change rate is smaller than that caused by increasing precipitation. Overall, the change rate of the runoff varies greatly with the change in the precipitation. Simulation results show that when temperature decreases by $1{ }^{\circ} \mathrm{C}$ and precipitation increases by $20 \%$, the runoff rate is the highest $(40 \%)$.

Table 1 SWIM runoff sensitivities given different levels of precipitation recorded at meteorological stations in the upper reaches of the HRB

\begin{tabular}{cccccc}
\hline \multirow{2}{*}{$\Delta t\left({ }^{\circ} \mathrm{C}\right)$} & \multicolumn{5}{c}{$\Delta p(\%)$} \\
\cline { 2 - 6 } & -20 & -10 & +0 & +10 & +20 \\
\hline+3 & -36.12 & -18.35 & 0.33 & 20.54 & 39.93 \\
+2 & -36.24 & -18.48 & 0.23 & 19.74 & 39.89 \\
+1 & -36.36 & -18.62 & 0.09 & 19.62 & 39.78 \\
0 & -36.48 & -18.72 & 0.00 & 19.08 & 39.73 \\
-1 & -36.29 & -18.53 & 0.21 & 19.81 & 40.00 \\
\hline
\end{tabular}

Data from Table 1 were standardized (Table 2) in order to determine the contribution rates of precipitation and temperature to runoff. To do this, any two groups of runoff change rates given a combination of precipitation and temperature were selected and the normalized re- 
sults substituted into simultaneous sensitivity coefficient equations. These steps enabled the calculation of runoff sensitivity to both precipitation and temperature; results show that when the sensitivity coefficient $\left(C_{v x}\right)$ of upstream runoff to temperature is between -0.098 and 0.269 , that of upstream runoff to precipitation $\left(C_{v y}\right)$ is between 0.909 and 1.145 .

Table 2 Standardized runoff sensitivity results for the upper reaches of the HRB

\begin{tabular}{cccccc}
\hline$\Delta p(\%)$ & \multicolumn{5}{c}{$\Delta t\left({ }^{\circ} \mathrm{C}\right)$} \\
\cline { 2 - 6 } & -1.2649 & -0.6324 & 0 & 0.6324 & 1.2649 \\
\hline 1.26491 & -1.3038 & -0.6559 & 0.0249 & 0.7619 & 1.4687 \\
0.63246 & -1.3083 & -0.6608 & 0.0213 & 0.7327 & 1.4675 \\
0 & -1.3128 & -0.6658 & 0.0161 & 0.7285 & 1.4635 \\
-0.63246 & -1.3171 & -0.6695 & 0.0130 & 0.7320 & 1.4614 \\
-1.26491 & -1.31028 & -0.6624 & 0.0208 & 0.7352 & 1.4713 \\
\hline
\end{tabular}

\subsubsection{Precipitation and temperature contribution rates}

We utilized the Tyson polygon method to analyze temperature changes in the upper reaches of the HRB over the last 50 years, between 1959 and 2008. To do this, we employed observational data from seven meteorological stations within this region. Although data reveal an average temperature of $15.3^{\circ} \mathrm{C}$ for the upper reaches of the $\mathrm{HRB}$, these values have been increasing (Figure 5) at a speed of $0.156^{\circ} \mathrm{C} / 10 \mathrm{a}$ over the study period. Thus, by applying the relative change in meteorological factors (Equation 1), we can see that the long-term relative temperature change is $4.91 \%$. Similarly, by applying Equation (2) to evaluate the influence of meteorological factors on runoff and Equation (3), the sensitivity coefficient of runoff and temperature, results show that the calculated contribution rate of temperature to the upper reaches of the HRB ranged between -0.005 and 0.01 . At the same time, the average annual precipitation in this region was $1060 \mathrm{~m}$ over the study period, conforming to a slight upward trend (Figure 5), while the long-term relative change in precipitation was $6.75 \%$. The sensitivity coefficient of runoff compared to precipitation shows that the contribution rate of the latter within the upper reaches of the HRB ranged between 0.061 and 0.077 .
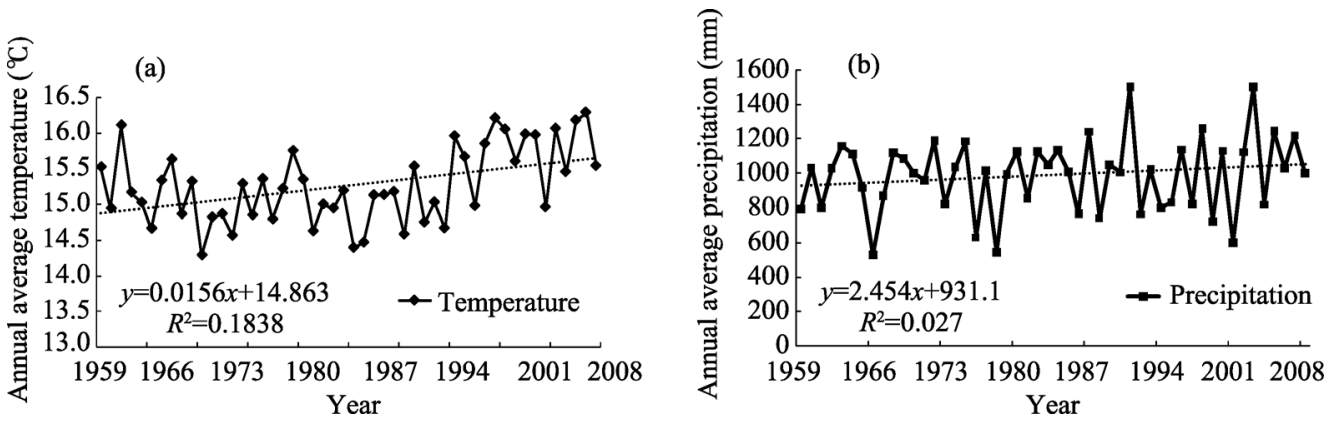

Figure 5 Trend in annual temperature (a) and precipitation (b) between 1959 and 2008

\subsection{Contribution rate of climatic factors in upstream-to-midstream runoff}

\subsubsection{Contribution rate of upstream-to-midstream runoff}

Based on daily runoff data collected at the Wangjiaba and Wujiadu stations between 1959 and 2008, we calculated the relative contribution rates of spring, summer, autumn, and win- 
ter runoff to the middle reaches of the HRB. These data are presented in Figure 6 and show that the contribution rates for the spring, summer, autumn, and winter seasons were $28.86 \%, 28.25 \%, 24.95 \%$, and $25.34 \%$, respectively. The highest contribution to overall runoff is in the spring, while the lowest contribution is in the autumn. The average annual contribution rate was $27.65 \%$.

4.3.2 Upstream climate change contribution rate to midstream runoff

The contribution rate of the precipitation and temperature from the upper reaches of the HRB to the midstream runoff was calculated by multiplying two contribution rates, the contribution rate of precipitation and

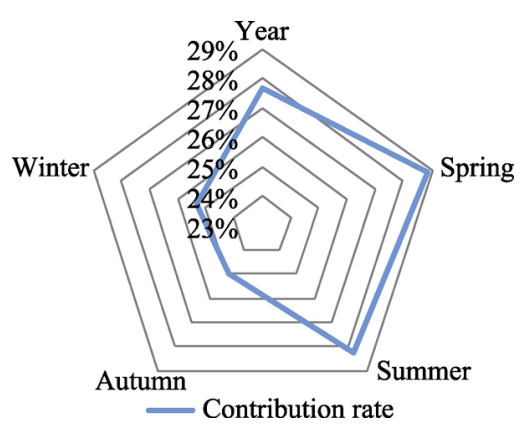

Figure 6 Contribution rates of spring, summer, autumn, and winter seasons to runoff in the middle and upper reaches of the HRB temperature to runoff in the upper basin regions and the contribution rate of upstream runoff to midstream runoff (Table 3 ). These results show that the maximum contribution rate of upstream precipitation to midstream runoff is about $2.23 \%$, while the minimum is about $1.53 \%$. Similarly, the maximum contribution rate of upstream temperature to runoff is about $0.38 \%$ while the minimum is about $-0.14 \%$.

Table 3 Contribution rates of upstream meteorological factors to midstream runoff

\begin{tabular}{ccccccc}
\hline & $\begin{array}{c}\text { Contribution rate of up- } \\
\text { stream meteorological } \\
\text { factors to runoff }(\%)\end{array}$ & \multicolumn{2}{l}{ Contribution rate of upstream meteorological factors to midstream runoff (\%) } \\
\cline { 3 - 7 } & Annual average & Spring & Summer & Autumn & Winter \\
\hline \multirow{2}{*}{ Precipitation } & $(\min ) 6.13$ & 1.70 & 1.77 & 1.73 & 1.53 & 1.55 \\
& $(\max ) 7.73$ & 2.14 & 2.23 & 2.18 & 1.93 & 1.96 \\
Temperature & $(\min )-0.48$ & -0.13 & -0.14 & -0.14 & -0.12 & -0.12 \\
& $(\max ) 1.32$ & 0.37 & 0.38 & 0.37 & 0.33 & 0.33 \\
\hline
\end{tabular}

These results show that the upstream HRB precipitation contribution rate to midstream runoff is higher than that of the temperature, while the maximum contribution rate of upstream precipitation (temperature) to runoff in the middle reaches is $2.23 \%(0.38 \%)$. These data show that runoff in the middle reaches of the HRB is not only influenced by upstream precipitation, but also by this process in middle river sections.

\subsection{Midstream runoff responses to climate change and human activities}

We determined the base and evaluation periods used in this study by analyzing runoff change points; land use data throughout these two periods were then input into our SWIM to simulate runoff. Runoff changes during the two periods were then calculated based on simulations in order to determine the contribution rates of climate change and human activities on the middle reaches of the HRB.

\subsubsection{Runoff change points}

In order to determine the base and evaluation periods in analyses of this type, runoff sequence change analysis has been applied in previous studies (Zhang et al., 2016). In this context, we applied MK and sliding T-tests to more accurately analyze and determine change 
points in runoff sequences.

The first of these tests (MK) was applied to annual runoff in the middle reaches of the HRB for the period between 1959 and 2008 (Figure 7). Although results reveal the presence of numerous intersections between Uf and Ub, no specific change years could be identified. However, re-analysis of annual runoff over this period in combination with use of a sliding T-test and selecting a step length of 6 , suggests that 1983 was a change year (significance level, $\alpha=0.05$ ). We therefore considered the period between 1959 and 1983 to be the base period for this study, while that between 1984 and 2008 was used as the evaluation period.
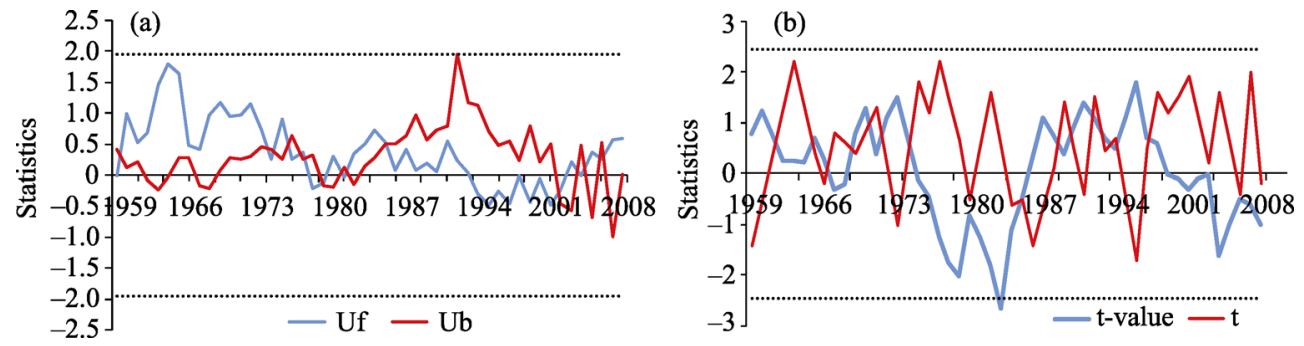

Figure 7 MK test results for runoff sequences (a), and the combined results of MK and sliding T-tests (b)

4.4.2 The effects of climate change and human activities on runoff

Calculations based on Equations (5)-(9) (Table 4) show that the base period for simulation is 7.627 $\times 10^{6} \mathrm{~m}^{3} \cdot \mathrm{s}^{-1}$. However, when the effects of climate change and human activities are taken into account, the evaluation period runoff is $7.041 \times$ $10^{6} \mathrm{~m}^{3} \cdot \mathrm{s}^{-1}$. The influence of human activities and climate change together on runoff during this period equated to $0.661 \times 10^{6} \mathrm{~m}^{3} \cdot \mathrm{s}^{-1}$; that of the former alone added up to $0.586 \times 10^{6} \mathrm{~m}^{3} \cdot \mathrm{s}^{-1}$, while that of the latter equated to $0.075 \times 10^{6}$ $\mathrm{m}^{3} \cdot \mathrm{s}^{-1}$.

These results enabled us to calculate the relative contribution rate of climate change and human activities to runoff in the middle reaches of the HRB (Table 5). Data reveal a 12.80\% contribution rate of the former and an $87.20 \%$ rate of the latter; thus, we can conclude that runoff within the middle reaches of the HRB is predominantly affected by human activities, while the influence of climate change is relatively small. This result is consistent with that for the upper reaches.

Table 5 Contribution rates of climate change and human activities to the HRB midstream runoff

\begin{tabular}{|c|c|c|c|c|}
\hline \multirow{2}{*}{ Total variation $\left(10^{6} \mathrm{~m}^{3} \cdot \mathrm{s}^{-1}\right)$} & \multicolumn{2}{|c|}{ Climate change } & \multicolumn{2}{|c|}{ Human activities } \\
\hline & Variation $\left(10^{6} \mathrm{~m}^{3} \cdot \mathrm{s}^{-1}\right)$ & Contribution rate & Variation $\left(10^{6} \mathrm{~m}^{3} \cdot \mathrm{s}^{-1}\right)$ & Contribution rate \\
\hline 0.661 & 0.075 & $12.80 \%$ & 0.586 & $87.20 \%$ \\
\hline
\end{tabular}

Data presented in the Huaihe River Water Resources Bulletin (http:/www.hrc.gov.cn/) shows that the number of large- and medium-sized reservoirs increased from 287 to 322 within the HRB between 1997 and 2000. Similarly, the total reservoir capacity within the 
region increased from $10.9 \times 10^{9} \mathrm{~m}^{3}$ in 1997 to $13.5 \times 10^{9} \mathrm{~m}^{3}$ in 2015 , while the amount of surface water supply increased from $39.0 \times 10^{9} \mathrm{~m}^{3}$ in 1998 to $43.8 \times 10^{9} \mathrm{~m}^{3}$ in 2015 . The data presented in Figure 8 shows that the surface water supply within the HRB has also increased rapidly over the past 20 years; thus, as the data in Figure 5 suggest no significant long-term increase in precipitation

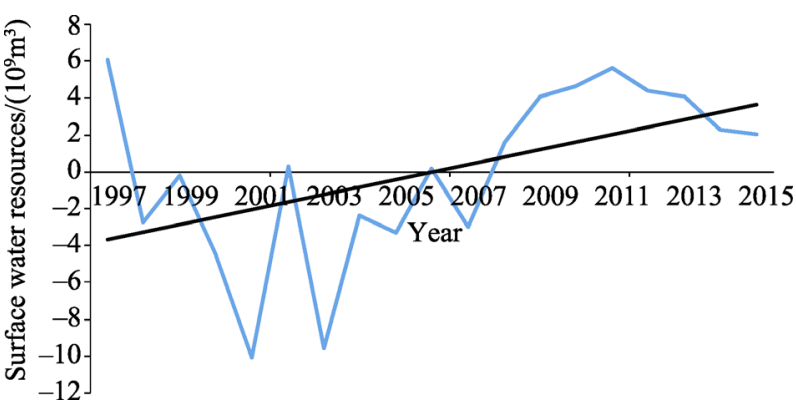

Figure 8 Anomalies in surface water resources in the HRB between 1997 and 2015 within the HRB, it is likely that the most significant impacts on the water supply in this region are from newly built reservoirs, industrial and agricultural water use, and other human activities.

\subsubsection{Causes of changes in runoff}

Data suggest two main causes for runoff changes in the middle reaches of the HRB, the effects of climate change and the impacts of human activities. The contribution rate of precipitation in the upper reaches of the HRB to the middle reaches runoff can reach $2.23 \%$ implies that the occurrence of flood-related disasters in the middle reaches is also influenced by the precipitation in the upper reaches. The results presented in this paper show that human activities exert a greater impact on runoff while climate change has a relatively smaller impact. In terms of land use change, a reduction of agricultural area combined with an increase in urban use was also evident throughout both the evaluation and base periods of this study. The data presented in Figure 9 shows that GDP, crop acreage, and the urbanization rate within the HRB all increased significantly between 1996 and 2015 . These changes are mainly the result of the rapid economic development characteristic of recent decades and have led to changes in the hydrological cycle.
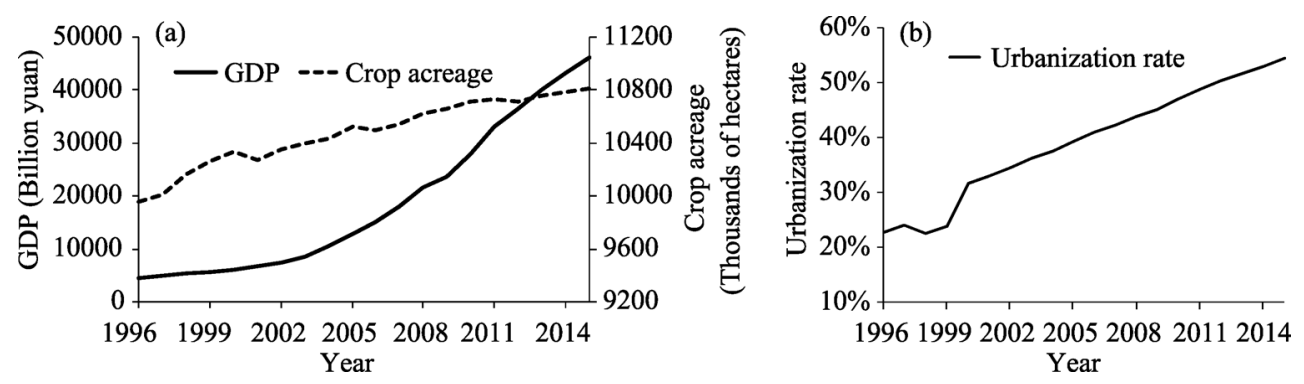

Figure 9 The changes in GDP, crop acreage, and the urbanization rate within the HRB between 1996 and 2015

\section{Discussion}

Considering the middle and upper reaches of the HRB, and utilizing daily meteorological data, runoff was simulated in this study using a SWIM. Thus, the contribution rate of climatic change to upstream-to-midstream runoff as well as the relative contribution rates of climate change and human activities to runoff were calculated. Combining SWIM outputs 
with further statistical analyses and taking the complex geographical environment of the region into account, this study quantitatively analyzed the impacts of climate change and human activities on the water resources of the HRB.

There are a number of similarities between the conclusions of this study and those of others; both climate change and human activities have been shown, for example, to have caused a decrease in river flow within the Chinese Loess Tableland, 24\% in the case of the former and $76 \%$ in the case of the latter (Li et al., 2010). Our results are consistent with the interpretation that anthropogenic factors are the main driving forces underlying decreases in river flow. In the Baiyangdian Lake, for example, quantitative results show that climatic variations can account for between $38 \%$ and $40 \%$ of streamflow decreases, while human activities can account for between $60 \%$ and $62 \%$ (Hu et al., 2012). Human activities are the major cause of runoff reductions over the last 50 years, encompassing contribution rates of up to $58.9 \%$ and $65.2 \%$, respectively, based on the two methods employed in this paper. Indeed, in light of different scenarios, the range of monthly runoff variation covers a wide range while the influence of precipitation change is stronger than that of temperature, indicating that the former is likely to be a major factor determining future variation in Beiluo River Basin water resources (Zhang et al., 2016). The impact of climate change and human activities on runoff is only likely to become stronger, as corroborated by research carried out Luanhe River catchment (Zhang et al., 2015). Nevertheless, some researchers have argued that climate change is the main factor underlying variation in runoff (Mo et al., 2016) and that this may also be caused by differences in geographical environments.

On the basis of quantitative analyses of the impacts of climate change, we conclude that floods in the middle reaches of the HRB are not just affected by climate change and human activities, but are also influenced by upstream changes in climate. Previous flood risk assessments of the HRB have employed daily maximum precipitation values obtained by fitting 20 kinds of distribution functions as major hazard factors and combining other indicators during different return periods. The predictions summarized in Figure 10 show that high-risk areas of extreme precipitation based on one-in-a-hundred and one-in-a-thousandyear events are concentrated in the upper reaches of the southwestern HRB (Zhang et al., 2014). At the same time, however, lower risk areas in the middle of the HRB are likely to be
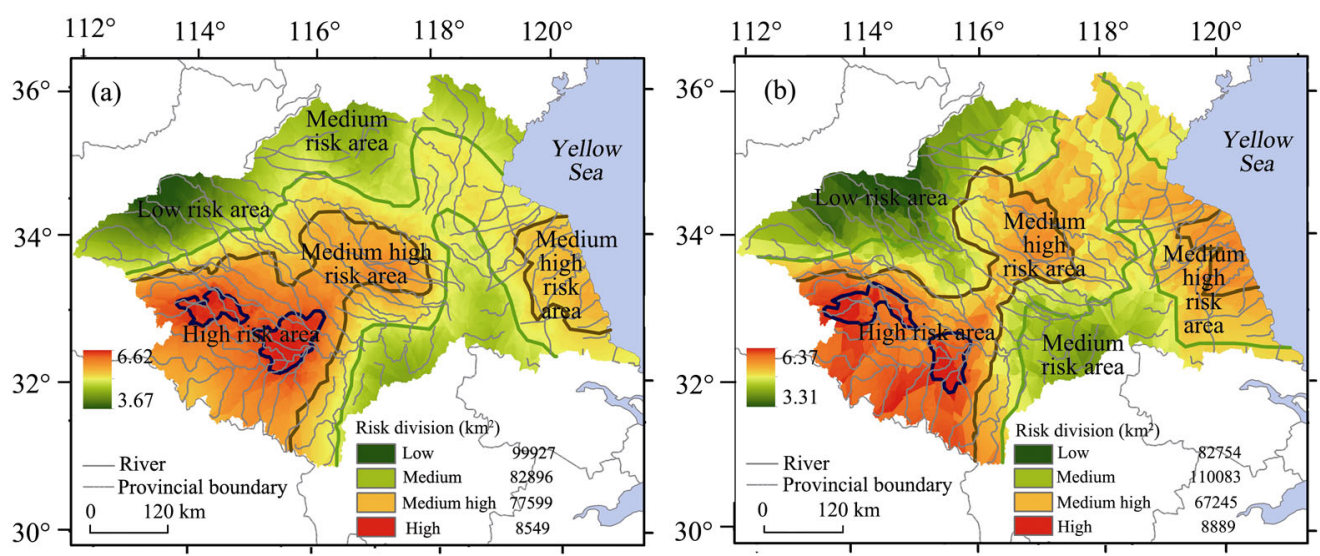

Figure 10 Risk assessment zoning maps for precipitation-related flooding disasters within the HRB over 100- (a) and 1000-year (b) return periods 
most severely affected by floods. This phenomenon may, in part, be due to the fact that the effect of extreme upstream precipitation on midstream runoff. Thus, it may be necessary to consider the actual situation in future flood risk assessments, incorporating the impact of upstream precipitation on the middle reaches rather than just emphasizing the central part of the river basin. These changes to the modeling approach would improve the effectiveness and accuracy of risk assessments and provide support for the development of flood disaster early warning systems.

\section{Conclusions}

(1) Sensitivity analysis results of runoff versus precipitation and temperature in the upper reaches of the HRB show that under different combination scenarios, the change rate of runoff increases with precipitation while temperature remains constant. At the same time, change in runoff is the largest when precipitation increases by $20 \%$. The sensitivity of runoff to precipitation is thus markedly higher than it is to temperature.

(2) Results show that the contribution rate of precipitation to midstream runoff in the upper reaches of the HRB is significantly higher than the contribution rate of temperature.

(3) The results of this study suggest that two main reasons can explain the frequent flood disasters that characterize the middle reaches of the HRB. In the first place, extreme precipitation occurs frequently in this region, and this affects runoff in the middle reaches of the river basin. Secondly, intensified human activities in the middle reaches of the HRB have modified the normal circulation of natural runoff and evapotranspiration leading to a higher frequency of flood disasters.

\section{References}

Aamery N Al, Fox J F, Snyder M, 2016. Evaluation of climate modeling factors impacting the variance of streamflow. Journal of Hydrology, 542: 125-142.

Ahn K H, Merwade V, 2017. The effect of land cover change on duration and severity of high and low flows. Hydrological Processes, 31(1): 133-149.

Bao Z X, Zhang J Y, Wang G Q et al., 2012. Attribution for decreasing streamflow of the Haihe River basin, northern China: Climate variability or human activities? Journal of Hydrology, 460/461(3): 117-129.

Bi Caixia, Mu Xingmin, Zhao Guangju et al., 2013. Effects of climate change and human activity on streamflow in the Wei River basin. Science of Soil and Water Conservation, 11(2): 33-38. (in Chinese)

Birkinshaw S J, Guerreiro S B, Nicholson A et al., 2017. Climate change impacts on Yangtze River discharge at the Three Gorges Dam. Hydrology and Earth System Sciences, 21(4): 1911-1927.

Chen Xiaohong, Tu Xinjun, Xie Ping et al., 2010. Progresses in the research of human induced variability of hydrological elements. Advances in Earth Science, 25(8): 800-811. (in Chinese)

Deng H J, Chen Y N, 2017. Influences of recent climate change and human activities on water storage variations in Central Asia. Journal of Hydrology, 544: 46-57.

Dong Xuguang, Gu Weizong, Wang Jing et al., 2015. Quantitative analysis of climate factors for potential evapotranspiration changes in Shandong. Journal of Natural Resources, 30(5): 810-823. (in Chinese)

Gao Chao, Jin Gaojie, 2012. Effects of DEM resolution on results of the SWIM hydrological model in the Changtaiguan basin. Geographical Research, 31(3): 399-408. (in Chinese)

Gao C, Zhang Z T, Zhai J Q et al., 2015. Research on meteorological thresholds of drought and flood disaster: A case study in the Huai River basin, China. Stochastic Environmental Research and Risk Assessment, 29(1): $157-167$.

Gao L M, Zhang Y N, 2016. Spatio-temporal variation of hydrological drought under climate change during the period 1960-2013 in the Hexi Corridor, China. Journal of Arid Land, 8(2): 157-171.

He Hui, Liao Xueping, Lu Hong et al., 2016. Features of long-cycle drought-flood abrupt alternation in South China during summer in 1961-2014. Acta Geographica Sinica, 71(1): 129-141. (in Chinese)

He Ruimin, Zhang Jianyun, Bao Zhenxin et al., 2015. Response of runoff to climate change in the Haihe River basin. Advances in Water Science, 26(1): 1-9. (in Chinese) 
Hu S S, Liu C M, Zheng H X et al., 2012. Assessing the impacts of climate variability and human activities on streamflow in the water source area of Baiyangdian Lake. Journal of Geographical Sciences, 22(5): 895-905.

Juckem P F, Hunt R J, Anderson M P et al., 2008. Effects of climate and land management change on streamflow in the driftless area of Wisconsin. Journal of Hydrology, 355(1-4): 123-130.

Krysanova V, Meiner A, Roosaare J et al., 1989. Simulation modelling of the coastal waters pollution from agricultural watershed. Ecological Modelling, 49(1/2): 7-29.

Lan Yongchao, Shen Yongping, Zhong Yingjun et al., 2010. Sensitivity of the mountain runoff of Urumqi River to the climate changes. Journal of Arid Land Resources and Environment, 24(11): 50-55. (in Chinese)

Liew M W V, Garbrecht J, 2003. Hydrologic simulation of the Little Washita River experimental watershed using SWAT. Journal of the American Water Resources Association, 39(2): 413-426.

Li K Y, Coe M T, Ramankutty N et al., 2007. Modeling the hydrological impact of land-use change in West Africa. Journal of Hydrology, 337(3/4): 258-268.

Li Zhi, Liu Wenzhao, Zheng Fenli et al., 2010. The impacts of climate change and human activities on river flow in the Loess Tableland of China. Acta Ecologica Sinica, 30(9): 2379-2386. (in Chinese)

López-Moreno J I, Zabalza J, Vicente-Serrano S M et al., 2014. Impact of climate and land use change on water availability and reservoir management: Scenarios in the Upper Aragón River, Spanish Pyrenees. Science of the Total Environment, 493: 1222-1231.

Lu Miao, Gao Chao, Su Buda et al., 2015. Spatial distribution and probabilistic characteristics of extreme precipitation in the Huaihe River basin. Journal of Natural Disasters, 24(5): 160-168. (in Chinese)

Ma C K, Sun L, Liu S Y et al., 2015. Impact of climate change on the streamflow in the glacierized Chu River Basin, Central Asia. Journal of Arid Land, 7(4): 501-513.

Mladjic B, Sushama L, Khaliq M N et al., 2011. Canadian RCM projected changes to extreme precipitation characteristics over Canada. Journal of Climate, 24(10): 2565-2584.

Mo Shuhong, Wang Xuefeng, Gou Kui et al., 2016. Impacts of climate changes and human activities on annual runoff of Bahe River basin. Journal of Hydroelectric Engineering, 35(9): 7-17. (in Chinese)

Piao S L, Ciais P, Huang Y et al., 2010. The impacts of climate change on water resources and agriculture in China. Nature, 467(7311): 43-51.

Pierrehumbert R T, 2002. The hydrologic cycle in deep-time climate problems. Nature, 419(6903): 191-198.

Song Xiaomeng, Zhang Jianyun, Zhan Chesheng et al., 2013. Review for impacts of climate change and human activities on water cycle. Journal of Hydraulic Engineering, 44(7): 779-790. (in Chinese)

Sun Yue, Li Dongliang, 2014. Features and response to climate-driven factors of the runoff in the upper reaches of the Weihe River in 1975-2011. Journal of Glaciology and Geocryology, 36(2): 413-423. (in Chinese)

Tong S T Y, Sun Y, Ranatunga T et al., 2012. Predicting plausible impacts of sets climate and land use change scenarios on water resources. Applied Geography, 32(2): 477-489.

Wang Guoqing, Wang Yunzhang, Kang Lingling, 2002. Analysis on the sensitivity of runoff in Yellow River to climate change. Journal of Applied Meteorological Science, 13(1): 117-121. (in Chinese)

Wang Guoqing, Zhang Jianyun, He Ruimin, 2006. Impacts of environmental change on runoff in the Fenhe River basin of the middle Yellow River. Advances in Water Science, 17(6): 853-858. (in Chinese)

Wang Sheng, Tian Hong, Ding Xiaojun et al., 2009. Climate characteristics of precipitation and phenomenon of drought-flood abrupt alternation during main flood season in Huaihe River basin. Chinese Journal of Agrometeorology, 30(1): 31-34. (in Chinese)

Wu D, Chen F H, Li K et al., 2016. Effects of climate change and human activity on lake shrinkage in Gonghe Basin of northeastern Tibetan Plateau during the past 60 years. Journal of Arid Land, 8(4): 479-491.

Xia Jun, 2009. Impact of water diversion project across basins on land water cycle and water security. Journal of Basic Science and Engineering, 17(6): 831-842. (in Chinese)

Yang L S, Feng Q, Yin Z L et al., 2017. Identifying separate impacts of climate and land use/cover change on hydrological processes in upper stream of the Heihe River, northwest China. Hydrological Processes, 31(1-5): $1100-1112$.

Zhang Guosheng, Li Lin, Shi Xinghe et al., 2000. Climatic changes over the upper Yellow River and its effects on water resources. Advances in Water Science, 11(3): 277-283. (in Chinese)

Zhang Jian, Li Tongsheng, Zhang Junhui et al., 2016. The runoff abrupt change and periodic characteristics of the Wudinghe River during 1933-2012. Acta Geographica Sinica, 36(3): 475-480. (in Chinese)

Zhang Lianpeng, Liu Dengfeng, Zhang Hongxue et al., 2016. Impact of climate change and human activities on runoff variation in the Beiluo River basin. Journal of Hydroelectric Engineering, 35(7): 55-66. (in Chinese)

Zhang Liping, Li Lingcheng, Xia Jun et al., 2015. Quantitative assessment of the impact of climate variability and human activities on runoff change in the Luanhe River catchment. Journal of Natural Resources, 30(4): 664-672. (in Chinese)

Zhang Shuifeng, Zhang Jinchi, Min Junjie et al., 2012. Drought-flood abrupt alternation based on runoff in the Huaihe River basin during rainy season. Journal of Lake Sciences, 24(5): 679-686. (in Chinese)

Zhang Zhengtao, Gao Chao, Liu Qing et al., 2014. Risk assessment on storm flood disasters of different return periods in Huaihe River basin. Geographical Research, 33(7): 1361-1372. (in Chinese) 